\title{
Chronic treatment with carvacrol improves passive avoidance memory in a rat model of Parkinson's disease
}

\author{
O tratamento com carvacrol melhora a memória de esquiva passiva em um modelo da \\ doença de Parkinson em ratos
}

Hossein Haddadi', Ziba Rajaei', Hojjatallah Alaei1', Somayeh Shahidani

\begin{abstract}
ABSCRACT
The present study investigated the effects of carvacrol on motor and memory deficits as well as hyperalgesia in the 6-OHDA-lesioned rat model of Parkinson's disease. The animals were subjected to unilateral microinjection of 6-OHDA into the medial forebrain bundle and treated with carvacrol (25, 50 and $100 \mathrm{mg} / \mathrm{kg}$, ip) for six weeks after surgery. The 6-OHDA-lesioned rats showed contralateral rotations towards the lesion side, which was accompanied by learning and memory deficits in a passive avoidance test and a decrease in tail withdrawal latency in a tail flick test at the end of week 6 . The results also showed that treatment with carvacrol at a dose of $25 \mathrm{mg} / \mathrm{kg}$ ameliorated memory deficits, with no effect on rotations and hyperalgesia in lesioned rats. In conclusion, carvacrol improves memory impairments in rats with Parkinson's disease; therefore, it may serve as an adjunct therapy for the alleviation of memory deficits in Parkinson's disease patients.
\end{abstract}

Keywords: Carvacrol; 6-hydroxydopamine; memory; motor activity; hyperalgesia; Parkinson's disease.

\section{RESUMO}

O presente estudo investigou os efeitos do carvacrol nos déficits motores e de memória, bem como na hiperalgesia, em um modelo da doença de Parkinson (DP) em ratos com lesões 6-OHDA. Os animais foram submetidos a microinjeção unilateral de 6-OHDA no feixe mediano do prosencéfalo e tratados com carvacrol (25, 50 e $100 \mathrm{mg} / \mathrm{kg}$, ip) durante 6 semanas após a cirurgia. Os ratos com lesões 6 -OHDA mostraram rotações contralaterais para o lado da lesão, que foram acompanhadas de déficits de aprendizagem e de memória em um teste de evitação passiva, e de uma diminuição da latência de retirada da cauda em um teste de cauda no final da semana 6 . Os resultados também mostraram que o tratamento crônico com carvacrol a uma dose de $25 \mathrm{mg} / \mathrm{kg}$ aliviou os déficits de memória, sem efeito sobre rotações e hiperalgesia em ratos lesados. Em conclusão, o carvacrol melhora a deficiência de memória em ratos com DP e, portanto, pode servir como uma terapia complementar para aliviar os déficits de memória em pacientes com DP.

Palavras-chave: Carvacrol; 6-hidroxidopamina; memória; atividade motora; hiperalgesia; doença de Parkinson.

Parkinson's disease (PD) is a chronic neurodegenerative disorder, which is caused mainly by the degeneration of dopaminergic neurons in the substantia nigra, leading to motor dysfunctions such as resting tremor, muscle rigidity and bradykinesia ${ }^{1}$. In addition to motor dysfunctions, cognitive deficits such as learning and memory impairments and dementia are seen in a high percentage of PD patients ${ }^{2}$. The proportion of PD patients with dementia is $25-30 \%$, up to six times higher than in healthy people ${ }^{3}$. Moreover, PD patients suffer from painful sensations that have been described as five different types: musculoskeletal pain (due to parkinsonian rigidity, rheumatological disease or skeletal deformity), radicular-neuropathic pain (due to a root lesion, focal or peripheral neuropathy), dystonic pain (related to antiparkinsonian medication), central neuropathic pain (related to antiparkinsonian medication) and akathisia (during offperiods or drug induced) $)^{4}$.

Pharmacotherapy with L-DOPA and DOPA-decarboxylase inhibitors is still the most effective treatment for motor symptoms, but this type of therapy has no effect on cognitive deficits in $\mathrm{PD}^{5,6}$. Considering the clear impact of cognitive deficits on the quality of the PD patient's life, it is valuable to investigate the treatments affecting non-motor symptoms, such as cognitive deficits and pain, in animal models of PD.

Carvacrol (CAR, 2-methyl-5-isopropylphenol) is a phenolic monoterpene abundantly present in the essential oil of the

${ }^{1}$ Isfahan University of Medical Sciences, School of Medicine, Department of Physiology, Isfahan, Iran.

Correspondence:Ziba Rajaei; Department of Physiology, School of Medicine, Isfahan University of Medical Sciences, Isfahan, Iran; E-mail: rajaeiz@med.mui.ac.ir Conflict of interest: There is no conflict of interest to declare.

Received 09 May 2017; Received in final form 29 October 2017; Accepted 08 November 2017.

Support: This study was supported by Isfahan University of Medical Sciences. 
family lamiaceae. Carvacrol has been reported to have many pharmacological benefits, including antibacterial, antifungal, antioxidant, antinociceptive, anti-inflammatory, anti-apoptosis and anti-cancer activities ${ }^{7}$. Carvacrol also exerts several actions on the neuronal system including acetylcholinesterase inhibition ${ }^{8,9}$, as well as having anxiolytic ${ }^{10}$ and antidepressant ${ }^{11}$ properties. It also modulates central neurotransmitter pathways, such as dopaminergic, serotonergic and GABAergic systems?

Based on the antioxidant activity of carvacrol and its effects on cholinergic and dopaminergic systems, we decided to examine whether carvacrol could improve the motor and memory deficits and pain in the 6-OHDA model of Parkinson's disease.

\section{METHODS}

\section{Experimental animals}

The experimental animals used in the present study were adult male Wistar rats weighing 250-350 g. They were maintained at a controlled temperature $\left(22 \pm 2^{\circ} \mathrm{C}\right)$ with a 12 -hour dark/light cycle and had free access to water and food. The Ethics Committee for Animal Experiments at Isfahan University of Medical Sciences approved the study (Approval No. 194036) and all experiments were conducted in accordance with the National Institute of Health Guide for the Care and Use of Laboratory Animals (NIH Publication, 8th edition, 2011).

\section{Experimental design}

The animals were randomly assigned to five groups, as follows:

Group 1: sham-operated group (injection of $0.2 \%$ ascorbate-saline into the left medial forebrain bundle (MFB), $1 \%$ Tween 80 ip, $n=7$ );

Group 2: lesioned group (16 $\mu \mathrm{g}$ 6-OHDA into the MFB, $1 \%$ Tween 80 ip, n = 7);

Group 3: Carvacrol-treated lesioned group (16 $\mu \mathrm{g}$ 6-OHDA into the MFB, $25 \mathrm{mg} / \mathrm{kg}$ carvacrol ip, $\mathrm{n}=10$ );

Group 4: Carvacrol-treated lesioned group (16 $\mu \mathrm{g}$ 6-OHDA into the MFB, $50 \mathrm{mg} / \mathrm{kg}$ carvacrol ip, $\mathrm{n}=10$ );

Group 5: Carvacrol-treated lesioned group (16 $\mu \mathrm{g}$ 6-OHDA into the MFB, $100 \mathrm{mg} / \mathrm{kg}$ carvacrol ip, $\mathrm{n}=7$ ).

Carvacrol was emulsified with $1 \%$ Tween 80 (Sigma, USA) and dissolved in normal saline. The animals were treated with carvacrol at doses of 25, 50 and $100 \mathrm{mg} / \mathrm{kg}$, intraperitoneally, one week before the surgery until six weeks after surgery. The sham-operated group received $1 \%$ Tween 80 dissolved in normal saline at the same volume as the treated groups.

\section{Surgery and 6-OHDA lesion}

Under chloral hydrate (450 mg/kg, ip) anesthesia, rats were positioned in the stereotaxic apparatus (Stoelting, USA). The scalp was cleaned with an iodine solution and lidocaine was injected ( $2 \%$ solution, Sc). A midline skin incision was made with subsequent drilling of the skull. The 6-OHDA compound $(16 \mu \mathrm{g} / 4 \mu \mathrm{l} 0.2 \%$ ascorbate-saline) was injected into the left MFB by a Hamilton microsyringe according to the coordinates: AP: $-3.6 \mathrm{~mm}$; ML: $-1.8 \mathrm{~mm}$; DV: $-8.2 \mathrm{~mm}^{12}$. The rats in the sham-operated group also received an identical volume of the ascorbate-saline as the vehicle. The injection rate was $1 \mu \mathrm{l} / \mathrm{min}$ and the needle was kept in place for a further five minutes after injection for complete absorption of the toxin. After surgery, the rats were placed singly into a clean page and kept warm until recovery from anesthesia was complete.

\section{Apomorphine-induced rotations}

The hemiparkinsonian rats were diagnosed by observing the rotational behavior after an injection of apomorphine hydrochloride (Sigma-Aldrich, USA) at the end of the 2nd and 6th week after surgery. Apomorphine hydrochloride was dissolved in normal saline and injected intraperitoneally at a dose of $2 \mathrm{mg} / \mathrm{kg}$. On the test day, the animals were allowed to habituate to a transparent plexiglass container $(28 \times 28 \times 50 \mathrm{~cm})$ for 10 minutes. One minute after the injection of apomorphine, full rotations were counted at 10 minute intervals for 30 minutes in a dimly-lit, quiet room. The number of ipsilateral rotations was counted as positive scores and those of contralateral rotations as negative scores. The net number of rotations were defined as the difference between the rotations in both directions ${ }^{13}$.

\section{Passive avoidance memory}

Passive avoidance learning was assessed by a shuttle box at the end of week 6. The apparatus consisted of a light and a dark compartment, connected by a guillotine door. In the training session, animals were placed individually in the light compartment for one minute. After the opening of the door and the movement of the rat into the dark chamber, the door was closed and a $0.5 \mathrm{~mA}$ foot electric shock was delivered through the grid floor for three seconds. In the test session, each rat was again placed into the light compartment. The step-through latency to entering the dark compartment was measured as a positive index of memory performance, with a 300 second cut-off time ${ }^{14}$.

\section{Tail-flick test}

The animal's response to phasic pain was tested by measuring the latency of tail flick to a high intensity light beam. The test was performed with a Tail Flick instrument that gives an automatic recording of tail-flick latency to radiant heat. The animal was placed on the recording platform of the apparatus where it was kept under painless restraint, with its tail placed on the radiant heat window. When the animal flicked its tail, a photocell was activated and the time between activation of the heat source and tail flick latency was recorded. For each animal, the thermal stimulus was applied on three different parts of the tail and the latency was considered as the mean of three measurements ${ }^{15}$. A cut-off exposure time of 15 seconds was set to prevent tissue damage. 


\section{Dissection and homogenization}

After completion of the behavioral testing, the animals were euthanized and the brains were removed from the skulls on day 42 . The striatum was dissected out and weighed. A $10 \%(\mathrm{w} / \mathrm{v})$ tissue homogenate was prepared in $\mathrm{NaCl}$ solution.

\section{Lipid peroxidation levels}

The lipid peroxidation level of the striatum was measured as malondialdehyde, which reacts with thiobarbituric acid as a thiobarbituric acid reactive substance (TBARS) to produce a red-colored complex that has a peak absorbance (A) at $535 \mathrm{~nm}$. A mixture of trichloroacetic acid, thiobarbituric acid, and $\mathrm{HCl}$ were added to $1 \mathrm{ml}$ of homogenate, and the mixture was heated for 45 minutes in a boiling water bath. After cooling and centrifugation at $1000 \mathrm{~g}$ for 10 minutes, the absorbance was measured at $535 \mathrm{~nm}^{16}$. The level of TBARS was calculated by: $\mathrm{C}(\mathrm{M})=$ absorbance $/ 1.65 \times 10^{5}$.

\section{Total thiol concentration}

Total sulfhydryl groups were measured using $2.2^{\prime}$-Dinitro$5.5^{\prime}$-dithiodibenzoic acid (DTNB) as the reagent. This reagent reacts with the sulfhydryl groups to produce a yellow-colored complex that has a peak absorbance at $412 \mathrm{~nm}$. Briefly, $1 \mathrm{ml}$ tris-EDTA buffer was added to $50 \mu \mathrm{l}$ homogenate and the sample absorbance was read at $412 \mathrm{~nm}$ against the tris-EDTA buffer alone (A1). Then, $20 \mu$ l of the DTNB reagent (10 $\mathrm{mM}$ in methanol) was added to the mixture and after 15 min (minutes), the sample absorbance was read again (A2). The absorbance of the DTNB reagent was also read as a blank (B). The total thiol concentration $(\mathrm{mM})$ was calculated by: $\left(\right.$ A2-A1-B) $\times 1.07 / 0.05 \times 13.6^{16}$.

\section{Histology}

The brains were removed and stored in $10 \%$ formalin for 72 hours. The brains were sectioned coronally at $40 \mu \mathrm{m}$ by a freezing microtome (Leica, Germany). Sections were mounted on gelatin-coated slides and studied using a light microscope. The track of the needle and the injection site of 6-OHDA (Figure 1) was determined by reference to a rat brain atlas ${ }^{12}$.

\section{Statistical analysis}

The results are presented as mean \pm SEM. Data were analyzed by one-way ANOVA followed by Tukey's post hoc test. Results were considered significant at $\mathrm{P}<0.05$.

\section{RESULTS}

\section{Effects of carvacrol on rotational behavior}

The results showed that apomorphine hydrochloride administration $(2 \mathrm{mg} / \mathrm{kg}$, ip) produced contralateral rotations towards the lesion side in 6-OHDA-lesioned rats at the end of the 2nd (Figure 2A) and 6th week (Figure 2B), indicating unilateral damage to the left MFB. No such rotations were observed in the sham group rats.

Analyzing data with one-way ANOVA revealed a significant difference in rotations between groups $(\mathrm{p}<0.001)$ at weeks 2 and 6. Further analysis with Tukey's post hoc test showed that the number of contralateral rotations in the 6-OHDA-lesioned group and the carvacrol-treated lesioned groups were significantly increased compared to the sham group ( $\mathrm{p}<0.001)$ at weeks 2 and 6 , but there was no difference between the treated and not-treated groups (Figures $2 \mathrm{~A}$ and $2 \mathrm{~B})$.

\section{Effects of carvacrol on passive avoidance memory}

As shown in Figure 3, the step-through latency of 6-OHDAlesioned rats $(128.8 \pm 47.38)$ was shorter than the sham group rats $(293 \pm 7)$ at the end of week 6 ( $<<0.05$, Figure 3$)$. Moreover, treatment of lesioned rats with carvacrol at a dose of $25 \mathrm{mg} / \mathrm{kg}$ significantly increased the latency $(281 \pm 19)$ compared with lesioned rats $(128.8 \pm 47.38)(\mathrm{p}<0.05)$.

\section{Effects of carvacrol on tail flick latency}

According to the results, there was a significant decrease in tail flick latency in 6-OHDA-lesioned rats compared to sham group rats at week 6 ( $p<0.05$, Figure 4$)$. No significant difference in latency to tail flick was observed following carvacrol administration in the 6-OHDA-lesioned groups (Figure 4).

\section{Effects of carvacrol on lipid peroxidation levels}

Injection of 6-OHDA into the MFB resulted in significant elevation of TBARS level in the striatum $(p<0.05)$. In addition, the results showed that treatment of lesioned rats with carvacrol at doses of 25,50 and $100 \mathrm{mg} / \mathrm{kg}$ for six weeks did not change the increased TBARS level in the striatum (Figure 5).

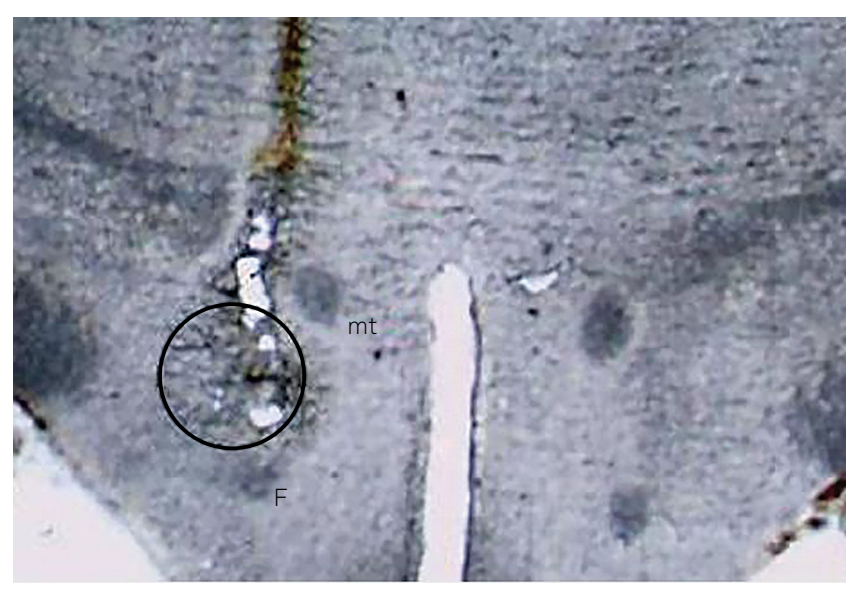

mt: mammilothalamic tract, F: fornix.

Figure 1. Photograph of the coronal section of a rat brain representing the injection site of 6-OHDA in the medial forebrain bundle (open circle). 
A

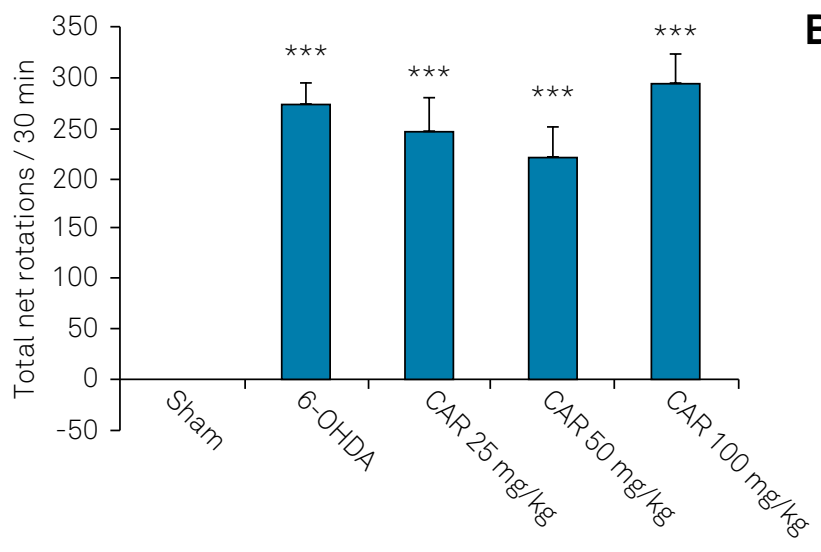

2 weeks after surgery

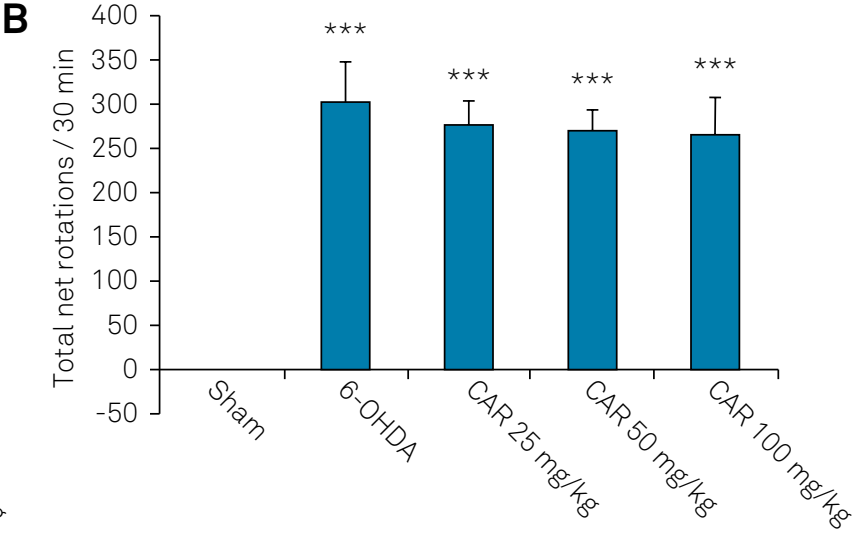

6 weeks after surgery

$\star * * p<0.001$ vs sham group.

Figure 2. Apomorphine-induced rotations in the sham, 6-OHDA-lesioned group and carvacrol-treated lesioned groups at the end of the $2 \mathrm{nd}(2 \mathrm{~A})$ and 6 th (2B) week after surgery. Carvacrol was administered ip daily at doses of 25, 50 and $100 \mathrm{mg} / \mathrm{kg}$.

\section{Effects of carvacrol on total thiol concentration}

Total thiol concentrations in the striatum were significantly decreased in the 6-OHDA-lesioned animals compared to the sham group $(\mathrm{p}<0.05)$. Treatment of lesioned rats with carvacrol at doses of 25, 50 and $100 \mathrm{mg} / \mathrm{kg}$ for six weeks did not change the decreased total thiol concentrations in the striatum (Figure 6).

\section{DISCUSSION}

It has been demonstrated that 6-OHDA causes the degeneration of nigrostriatal dopaminergic neurons and produces motor and non-motor impairments such as cognitive deficits similar to those observed in patients with $\mathrm{PD}^{14,17,18}$. Therefore, it was used as a valid model of PD. Our results also confirmed these changes. The administration of

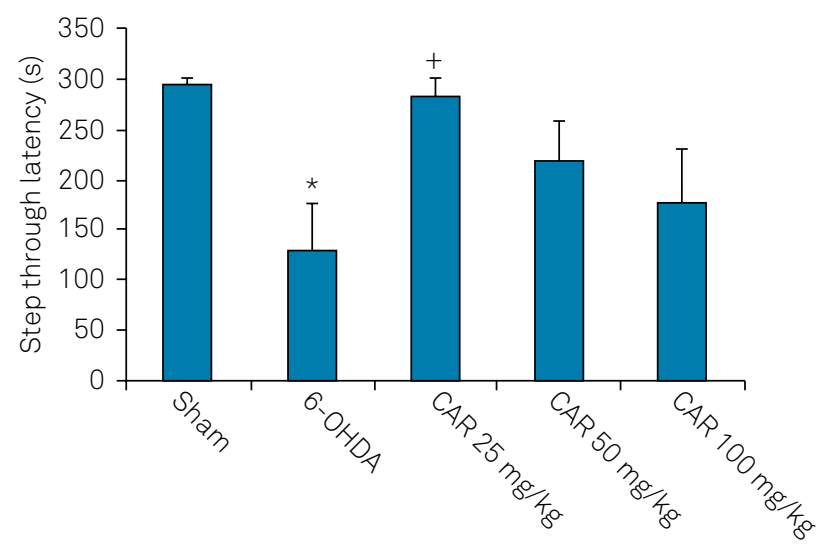

${ }^{*} \mathrm{p}<0.05$ vs sham group, $+\mathrm{p}<0.05$ vs 6 -OHDA-lesioned group.

Figure 3. Step-through latencies in the passive avoidance test in the sham, 6-OHDA-lesioned rats and lesioned rats treated with carvacrol at doses of 25,50 and $100 \mathrm{mg} / \mathrm{kg}$ at the end of week 6. Data are mean \pm SEM.
6-OHDA into the MFB produced motor and memory deficits and reduced the pain threshold.

The 6-OHDA compound is a dopaminergic neurotoxin that undergoes auto-oxidation and produces cytotoxic hydrogen peroxide, reactive oxygen species and catecholamine quinones, which attack intracellular nucleophilic groups ${ }^{19}$. The increase in reactive oxygen species levels causes abnormalities in cell structure and metabolism and eventually leads to neuronal degeneration ${ }^{20}$. In line with this, our results showed that microinjection of 6-OHDA into the MFB caused oxidative damage to the membrane, as evidenced by increased levels of TBARS and decreased total thiol concentration in the striatum at the end of week 6 .

In the present study, the microinjection of 6-OHDA into the left MFB resulted in motor deficits that were observed by increased rotations. The unilateral lesion of the nigrostriatal

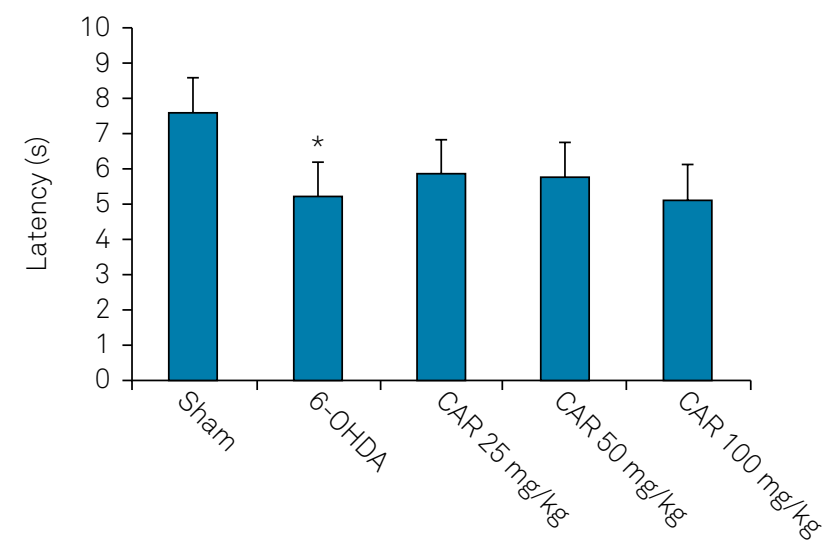

${ }^{*} p<0.05$ vs sham group.

Figure 4. Tail flick latencies in the sham, 6-OHDA-lesioned rats and lesioned rats treated with carvacrol at doses of 25, 50 and $100 \mathrm{mg} / \mathrm{kg}$ at the end of week 6 . Data are mean \pm SEM. 


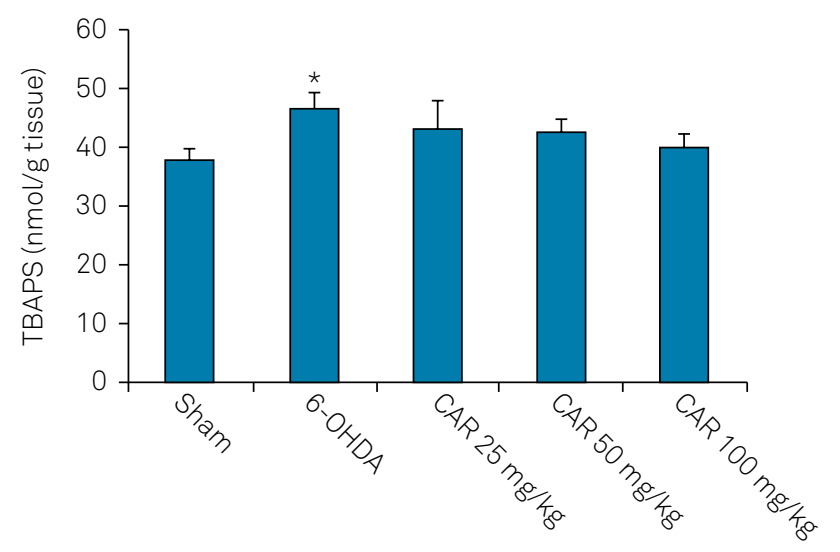

${ }^{*} \mathrm{p}<0.05$ vs sham group.

Figure 5. Lipid peroxidation levels in the striatum of the sham, 6-OHDA-lesioned rats and lesioned rats treated with carvacrol at doses of 25, 50 and $100 \mathrm{mg} / \mathrm{kg}$ at the end of week 6. Data are mean \pm SEM.

dopaminergic system by 6-OHDA decreases dopamine levels in the striatum and upregulates dopamine postsynaptic receptors on the same side. These changes produce a motor asymmetry that can be evaluated by dopamine agonists such as apomorphine ${ }^{21}$. Apomorphine-induced rotations in 6-OHDA-lesioned rats is a reliable marker for the nigrostriatal dopamine depletion. The symptoms of PD appear when about $60-80 \%$ of the dopamine levels and 50-60\% of dopaminergic neurons in the substantia nigra are lost ${ }^{22}$.

The present study also examined the potential therapeutic effect of carvacrol, as an antioxidant agent, in a 6-OHDA model of PD. Our results showed that treatment with carvacrol at doses of 25, 50 and $100 \mathrm{mg} / \mathrm{kg}$ did not decrease the apomorphine-induced rotations in rats. This is in contrast to prior studies, which report the protective effects of carvacrol on oxidative insults such as cerebral ischemia-reperfusion ${ }^{23}$. The reasons for this discrepancy could be related to the

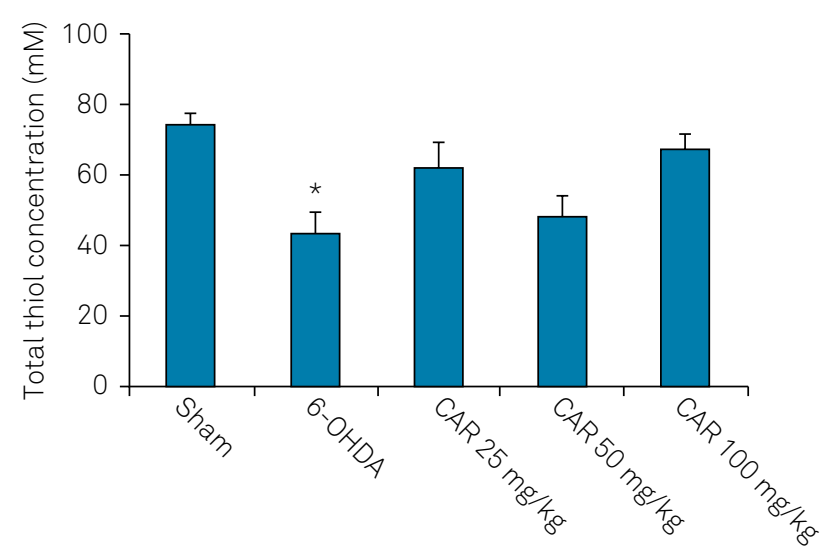

${ }^{\star} p<0.05$ vs sham group.

Figure 6. Total thiol concentrations in the striatum of the sham, 6-OHDA-lesioned rats and lesioned rats treated with carvacrol at doses of 25,50 and $100 \mathrm{mg} / \mathrm{kg}$ at the end of week 6. Data are mean \pm SEM. dosage and duration of treatment. The initial oxidative stress produced by 6-OHDA might be attenuated by the antioxidant activity of carvacrol; however, when there is substantial ongoing oxidative stress and neurodegeneration ${ }^{24}$ - as in the 6-OHDA model of PD - the antioxidant response wanes or is overwhelmed over time and, at that point, carvacrol cannot act as an antioxidant.

Furthermore, our results also showed that unilateral lesion to the left MFB significantly reduced the pain sensation threshold in the tail flick test. This is consistent with previous findings, which have reported that bilateral 6-OHDA lesions decreased the latency of the hind paw lick in the hot plate test ${ }^{25}$ and enhanced sensitivity to a wide range of thermal and mechanical painful stimuli ${ }^{26}$. The precise mechanisms underlying alteration in the withdrawal response to thermal and mechanical stimulation in the 6-OHDA rats is unclear. Neurophysiological, clinical and behavioral experiments indicate that, other than motor control, the basal ganglia are also involved in pain processing ${ }^{27}$. Experimental studies have shown that striatal dopamine is important for modulating nociceptive behavioral responses ${ }^{27}$, an effect that appears mediated through dopamine D2 receptors ${ }^{25}$. The striatum has direct and indirect efferent connections to various brainstem structures involved in the descending pain modulation system ${ }^{27}$. It has been suggested that the upregulation of dopamine D2 receptors in the striatum in the 6-OHDA rats may lead to a decrease in the activity of the descending pain modulation system.

In the present study, the unilateral 6-OHDA lesioned rats were treated with carvacrol to evaluate its possible effect on pain sensation in an animal model of PD. The results showed that treatment with carvacrol did not change the pain sensation threshold in the tail flick test in PD animals. This could also be attributed to the lack of antioxidant activity of carvacrol in this study.

Moreover, cognitive decline is a main non-motor symptom of PD that predisposes the majority of patients to progression into dementia ${ }^{28}$. Parkinson's disease patients complain of executive dysfunction and deficiencies of working memory that resemble those created by frontal lobe injury ${ }^{29}$. The 6-OHDA-induced neuronal loss in the substantia nigra has also been shown to result in learning and memory impairments ${ }^{14,30}$. In line with previous studies, our results also showed that short-term memory in the step-down avoidance task had deteriorated in the rats with 6-OHDA-induced PD, and treatment with carvacrol at a dose of $25 \mathrm{mg} / \mathrm{kg}$ improved short-term memory.

Cognitive deficits in PD patients might result from nondopaminergic dysfunction, as degeneration of noradrenergic, serotonergic and, most importantly, cholinergic systems have been reported in $\mathrm{PD}^{31}$. Significant loss of cholinergic forebrain neurons has been reported in PD-affected brains ${ }^{32}$. It also has been reported that the loss of cholinergic cells in the nucleus basalis of Meynert (where Lewy bodies are frequently found) 
is greater than that seen in Alzheimer's disease ${ }^{33}$. The nucleus basalis of Meynert is the main source of cholinergic projections to the cerebral cortex and degenerates in PD. In addition, choline acetyltransferase activity has been found to be significantly decreased in the cortex of parkinsonian subjects ${ }^{34}$.

Our findings indicated that carvacrol ameliorated short-term memory impairment in rats with PD. It has also been shown that carvacrol improved spatial memory impairments induced by scopolamine, a muscarinic receptor antagonist, in rats $^{35}$. More importantly, the acetylcholinesterase inhibitory activity of carvacrol has been shown in several studies ${ }^{8,9}$. Therefore, the effect of carvacrol on memory improvement could be due to its anticholinesterase activity and modulation of the cholinergic system. In agreement with this, it has been reported that acetylcholinesterase inhibitors have a beneficial effect on cognitive performance in $\mathrm{PD}^{36}$.

In conclusion, the present study demonstrated that carvacrol improves short-term memory impairment in rats with PD. Considering that L-DOPA therapy for PD just relieves motor symptoms, we suggest that carvacrol may serve as an adjunct therapy for the alleviation of memory deficits in patients with PD.

\section{Acknowledgements}

The results presented in this work have been taken from a student's thesis. This study was supported by Isfahan University of Medical Sciences.

\section{References}

1. Fahn S. Description of Parkinson's disease as a clinical syndrome. Ann N Y Acad Sci. 2003 Jun;991(1):1-14. https://doi.org/10.1111/j.1749-6632.2003.tb07458.x

2. Brown RG, Marsden CD. How common is dementia in Parkinson's disease? Lancet. 1984 Dec;2(8414):1262-5. https://doi.org/10.1016/S0140-6736(84)92807-1

3. Aarsland D, Andersen K, Larsen JP, Lolk A, Nielsen H, Kragh-Sørensen P. Risk of dementia in Parkinson's disease: a community-based, prospective study. Neurology. 2001 Mar;56(6):730-6. https://doi.org/10.1212/WNL.56.6.730

4. Beiske AG, Loge JH, Rønningen A, Svensson E. Pain in Parkinson's disease: prevalence and characteristics. Pain. 2009 Jan;141(1-2):173-7. https://doi.org/10.1016/j.pain.2008.12.004

5. Janvin CC. Cognitive impairment in patients with parkinson's disease: profiles and implications for prognosis. Bora - Uib. 2007 [acess year Month day]. Available from: http://bora.uib.no/handle/1956/2242

6. Kulisevsky J, Avila A, Barbanoj M, Antonijoan R, Berthier ML, Gironell A. Acute effects of levodopa on neuropsychological performance in stable and fluctuating Parkinson's disease patients at different levodopa plasma levels. Brain. 1996 Dec;119(Pt 6):2121-32. https://doi.org/10.1093/brain/119.6.2121

7. Baser $\mathrm{KH}$. Biological and pharmacological activities of carvacrol and carvacrol bearing essential oils. Curr Pharm Des. 2008;14(29):3106-19. https://doi.org/10.2174/138161208786404227

8. Jukic M, Politeo O, Maksimovic M, Milos M, Milos M. In vitro acetylcholinesterase inhibitory properties of thymol, carvacrol and their derivatives thymoquinone and thymohydroquinone. Phytother Res. 2007 Mar;21(3):259-61. https://doi.org/10.1002/ptr.2063

9. Kaufmann D, Dogra AK, Wink M. Myrtenal inhibits acetylcholinesterase, a known Alzheimer target. J Pharm Pharmacol. 2011 Oct;63(10):1368-71. https://doi.org/10.1111/j.2042-7158.2011.01344.x

10. Melo FH, Venâncio ET, Sousa DP, Fonteles MMF, Vasconcelos SM, Viana GS et al. Anxiolytic-like effect of Carvacrol (5-isopropyl-2-methylphenol) in mice: involvement with GABAergic transmission. Fundam Clin Pharmacol. 2010 Aug;24(4):437-43. https://doi.org/10.1111/j.1472-8206.2009.00788.x

11. Melo FH, Moura BA, Sousa DP, Vasconcelos SM, Macedo DS, Fonteles MM et al. Antidepressant-like effect of carvacrol (5-Isopropyl-2-methylphenol) in mice: involvement of dopaminergic system. Fundam Clin Pharmacol. 2011 Jun;25(3):362-7. https://doi.org/10.1111/j.1472-8206.2010.00850.x

12. Paxinos $G$, Watson $C$. The rat brain in stereotaxic coordinates. 5 th ed. Amsterdam, London: Elsevier Academic; 2005.
13. Fujita M, Nishino H, Kumazaki M, Shimada S, Tohyama M, Nishimura T. Expression of dopamine transporter mRNA and its binding site in fetal nigral cells transplanted into the striatum of 6-OHDA lesioned rat. Brain Res Mol Brain Res. 1996 Jul;39(1-2):127-36. https://doi.org/10.1016/0169-328X(96)00018-6

14. Rajaei Z, Hosseini M, Alaei H. Effects of crocin on brain oxidative damage and aversive memory in a 6-OHDA model of Parkinson's disease. Arq Neuropsiquiatr. 2016 Sep;74(9):723-9. https://doi.org/10.1590/0004-282X20160131

15. Tassorelli C, Greco R, Wang D, Sandrini M, Sandrini G, Nappi G. Nitroglycerin induces hyperalgesia in rats: time-course study. Eur J Pharmacol. 2003 Mar;464(2-3):159-62. https://doi.org/10.1016/S0014-2999(03)01421-3

16. Ahmadi M, Rajaei Z, Hadjzadeh MA, Nemati H, Hosseini M. Crocin improves spatial learning and memory deficits in the Morris water maze via attenuating cortical oxidative damage in diabetic rats. Neurosci Lett. 2017 Mar;642:1-6. https://doi.org/10.1016/j.neulet.2017.01.049

17. Campos FL, Carvalho MM, Cristovão AC, Je G, Baltazar G, Salgado AJ et al. Rodent models of Parkinson's disease: beyond the motor symptomatology. Front Behav Neurosci. 2013 Nov;7:175. https://doi.org/10.3389/fnbeh.2013.00175

18. Tadaiesky MT, Dombrowski PA, Figueiredo CP, Cargnin-Ferreira E, Da Cunha C, Takahashi RN. Emotional, cognitive and neurochemical alterations in a premotor stage model of Parkinson's disease. Neuroscience. 2008 Oct;156(4):830-40. https://doi.org/10.1016/j.neuroscience.2008.08.035

19. Palumbo A, Napolitano A, Barone P, Ischia M. Nitrite- and peroxide-dependent oxidation pathways of dopamine: 6-nitrodopamine and 6-hydroxydopamine formation as potential contributory mechanisms of oxidative stress- and nitric oxide-induced neurotoxicity in neuronal degeneration. Chem Res Toxicol. 1999 Dec;12(12):1213-22. https://doi.org/10.1021/tx990121g

20. Blum D, Torch S, Lambeng N, Nissou M, Benabid AL, Sadoul R et al. Molecular pathways involved in the neurotoxicity of 6-OHDA, dopamine and MPTP: contribution to the apoptotic theory in Parkinson's disease. Prog Neurobiol. 2001 Oct;65(2):135-72. https://doi.org/10.1016/S0301-0082(01)00003-X

21. Schwarting RK, Huston JP. Behavioral and neurochemical dynamics of neurotoxic meso-striatal dopamine lesions. Neurotoxicology. 1997;18(3):689-708.

22. Dauer W, Przedborski S. Parkinson's disease: mechanisms and models. Neuron. 2003 Sep;39(6):889-909. https://doi.org/10.1016/S0896-6273(03)00568-3 
23. Yu H, Zhang ZL, Chen J, Pei A, Hua F, Qian X et al. Carvacrol, a food-additive, provides neuroprotection on focal cerebral ischemia/reperfusion injury in mice. PLoS One. 2012;7(3):e33584. https://doi.org/10.1371/journal.pone.0033584

24. Sarre S, Yuan H, Jonkers N, Van Hemelrijck A, Ebinger G, Michotte $Y$. In vivo characterization of somatodendritic dopamine release in the substantia nigra of 6-hydroxydopamine-lesioned rats. J Neurochem. $2004 \mathrm{Jul} ; 90(1): 29-39$. https://doi.org/10.1111/j.1471-4159.2004.02471.x

25. Lin MT, Wu JJ, Chandra A, Tsay BL. Activation of striatal dopamine receptors induces pain inhibition in rats. J Neural Transm (Vienna). 1981;51(3-4):213-22. https://doi.org/10.1007/BF01248953

26. Takeda R, Ikeda T, Tsuda F, Abe H, Hashiguchi H, Ishida Y et al. Unilateral lesions of mesostriatal dopaminergic pathway alters the withdrawal response of the rat hindpaw to mechanical stimulation. Neurosci Res. 2005 May;52(1):31-6. https://doi.org/10.1016/j.neures.2005.01.005

27. Chudler EH, Dong WK. The role of the basal ganglia in nociception and pain. Pain. 1995 Jan;60(1):3-38. https://doi.org/10.1016/0304-3959(94)00172-B

28. Janvin CC, Larsen JP, Aarsland D, Hugdahl K. Subtypes of mild cognitive impairment in Parkinson's disease: progression to dementia. Mov Disord. 2006 Sep;21(9):1343-9. https://doi.org/10.1002/mds.20974

29. Lewis SJ, Cools R, Robbins TW, Dove A, Barker RA, Owen AM. Using executive heterogeneity to explore the nature of working memory deficits in Parkinson's disease. Neuropsychologia. 2003;41(6):645-54. https://doi.org/10.1016/S0028-3932(02)00257-9
30. Beppe GJ, Dongmo AB, Foyet HS, Tsabang N, Olteanu Z, Cioanca $\mathrm{O}$ et al. Memory-enhancing activities of the aqueous extract of Albizia adianthifolia leaves in the 6-hydroxydopamine-lesion rodent model of Parkinson's disease. BMC Complement Altern Med. 2014 Apr;14(1):142. https://doi.org/10.1186/1472-6882-14-142

31. Jokinen P, Brück A, Aalto S, Forsback S, Parkkola R, Rinne JO. Impaired cognitive performance in Parkinson's disease is related to caudate dopaminergic hypofunction and hippocampal atrophy. Parkinsonism Relat Disord. 2009 Feb;15(2):88-93. https://doi.org/10.1016/j.parkreldis.2008.03.005

32. Whitehouse PJ, Hedreen JC, White CL 3rd, Price DL. Basal forebrain neurons in the dementia of Parkinson disease. Ann Neurol. 1983 Mar;13(3):243-8. https://doi.org/10.1002/ana.410130304

33. Liu AK, Chang RC, Pearce RK, Gentleman SM. Nucleus basalis of Meynert revisited: anatomy, history and differential involvement in Alzheimer's and Parkinson's disease. Acta Neuropathol. 2015 Apr;129(4):527-40. https://doi.org/10.1007/s00401-015-1392-5

34. Dubois B, Danzé F, Pillon B, Cusimano G, Lhermitte F, Agid Y. Cholinergic-dependent cognitive deficits in Parkinson's disease. Ann Neurol. 1987 Jul;22(1):26-30. https://doi.org/10.1002/ana.410220108

35. Azizi Z, Ebrahimi S, Saadatfar E, Kamalinejad M, Majlessi N. Cognitive-enhancing activity of thymol and carvacrol in two rat models of dementia. Behav Pharmacol. 2012 Jun;23(3):241-9. https://doi.org/10.1097/FBP.0b013e3283534301

36. Lauretani F, Galuppo L, Costantino C, Ticinesi A, Ceda G, Ruffini L et al. Parkinson's disease (PD) with dementia and falls is improved by AChEl? A preliminary study report. Aging Clin Exp Res. 2016 Jun;28(3):551-5. https://doi.org/10.1007/s40520-015-0437-x 